SCIENTIFIC REPORT

\title{
Bupivacaine injection of eye muscles to treat strabismus
}

\author{
Alan B Scott, Danielle E Alexander, Joel M Miller
}

Br J Ophthalmol 2007;91:146-148. doi: 10.1136/bjo.2006.110619

Background: Bupivacaine injected into animal muscles induces a cycle of myotoxicity, degeneration, regeneration and hypertrophy of muscle fibres, without adverse effects on other tissues. This induced hypertrophy can be harnessed to treat strabismus.

Methods: Bupivacaine, $4.5 \mathrm{ml}$ of a $0.75 \%$ solution, was injected into the right lateral rectus (RLR) muscle of a patient who had diplopia and who showed 14-prism-dioptres oesotropia.

Results: RLR paresis persisted for 7 days. Then, the RLR regained its abducting ability, and progressive improvement of alignment to 4-prism-dioptres oesophoria occurred over the next 33 days, with the elimination of diplopia. Alignment remained the same at 54 days after injection. Magnetic resonance imaging showed a focal increase in the size of the injected RLR of $58 \%$ in the posterior area, with reduced change in anterior portions of the RLR.

Conclusion: Injection of bupivacaine to induce hypertrophy of the injected muscle and thus alter eye alignment was effective in our patient. This approach can be a useful addition to the treatment of strabismus.

B upivacaine injection into the muscles of laboratory animals has been reported by several authors to show specific myotoxicity for muscle fibres, leaving the basal lamina, nerves and satellite cells intact. ${ }^{1-3}$ Subsequent repair with satellite cell proliferation and eventual muscle hypertrophy then occurs, with some variability depending on the muscle fibre type, fast or slow. ${ }^{45}$ Eye muscles are also sometimes injected with bupivacaine during retrobulbar anaesthesia, with the resulting strabismus cases showing enlarged muscles. ${ }^{6-10}$ After appropriate institutional review board procedures, a protocol was established to experimentally test whether bupivacaine injection could be used to alter strabismus in humans in a beneficial way.

\section{CASE REPORT: METHODS AND RESULTS}

A woman started having horizontal diplopia at the age of 22 years. Prism glasses treated this successfully for 30 years. At age 56 years, diplopia became a problem, and left medial rectus recession and left lateral rectus resection were performed for 30-prism-dioptres oesotropia. A 4-prism-dioptres residual oesophoria was asymptomatic until age 66 years, with the oesotropia then increasing to 14-prism-dioptres concomitant oesotropia at age 72 years. Vision was $20 / 30$ in the right eye, reduced by mild cataract formation, and 20/40 in the left eye, reduced by a mild cataract and amblyopia. Fusion and stereopsis were present with prism correction. No evidence of neurological impairment was present, and magnetic resonance imaging of the brain and orbits was normal. Treatment with prism glasses, botulinum toxin injection or surgery was offered. After discussion regarding its experimental nature, informed consent was obtained for an experimental injection. Bupivacaine, $4.5 \mathrm{ml}$ of a $0.75 \%$ solution, was injected into the right lateral rectus (RLR) muscle, using the recording of muscle electrical activity from the needle tip to guide the location of the injection. Mild proptosis, a small subconjunctival haemorrhage, diminished abduction of the eye and a slight increase in oesotropia resulted. There was no change in vision and no pain. Abduction weakness persisted for 7 days, followed by recovery of motility and then reduction in the deviation. At 16 days after injection, the primary position deviation was 8-prism-dioptres oesotropia, and diplopia was no longer present. At 33 days after the injection, the deviation was further reduced to 4 prismdioptres oesophoria. It remained 4-prism-dioptres oesophoria at the most recent examination, 54 days after injection. Magnetic resonance imaging showed an increase in the size of the injected RLR. The cross-sectional area of the RLR in the posterior orbit before injection was $0.382 \mathrm{~cm}^{2}$; at 33 days after injection it was $0.609 \mathrm{~cm}^{2}$, an increase of $58 \%$. We used $\mathrm{NIH}$ public domain software, ImageJ, to make these measurements and comparisons. ${ }^{11}$ Reduced hypertrophy was evident in anterior magnetic resonance image slices (fig 1). The crosssectional area of the other muscles was unchanged.

\section{DISCUSSION}

Bupivacaine injection of muscle in laboratory animals results in immediate and massive degeneration of muscle fibres, with dissolution of myofibrils at the Z-band. ${ }^{12}$ Other structures are substantially unchanged, including the basal lamina, the satellite cells of which form the muscle fibres, and nearby nerves and vasculature. ${ }^{12-15}$ Inflammatory cells and macrophages remove the degenerated muscle fibres over 2-10 days time. ${ }^{215}$ Beginning at about day 2, satellite cells are activated and regeneration begins with the muscle reaching pre-injection size and strength around day $21 .{ }^{15}$ The satellite cells continue to elaborate new fibres, with the resulting hypertrophy continuing for many days, and with the muscle remaining enlarged for at least 180 days. $^{45}$ The participation of satellite cells in eye muscle function and the signals that control their activation are related fields of great interest. ${ }^{16}{ }^{17}$ We suppose that the strabismus after cataract surgery also results from muscle hypertrophy induced by bupivacaine. ${ }^{18}$ Fibrosis and

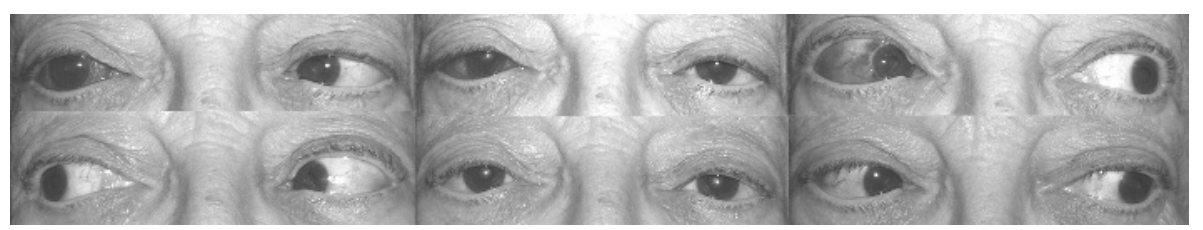

Figure 1 The patient immediately after bupivacaine injection (above), and at 33 days after injection (below). Informed patient consent was obtained for publication of this figure. 


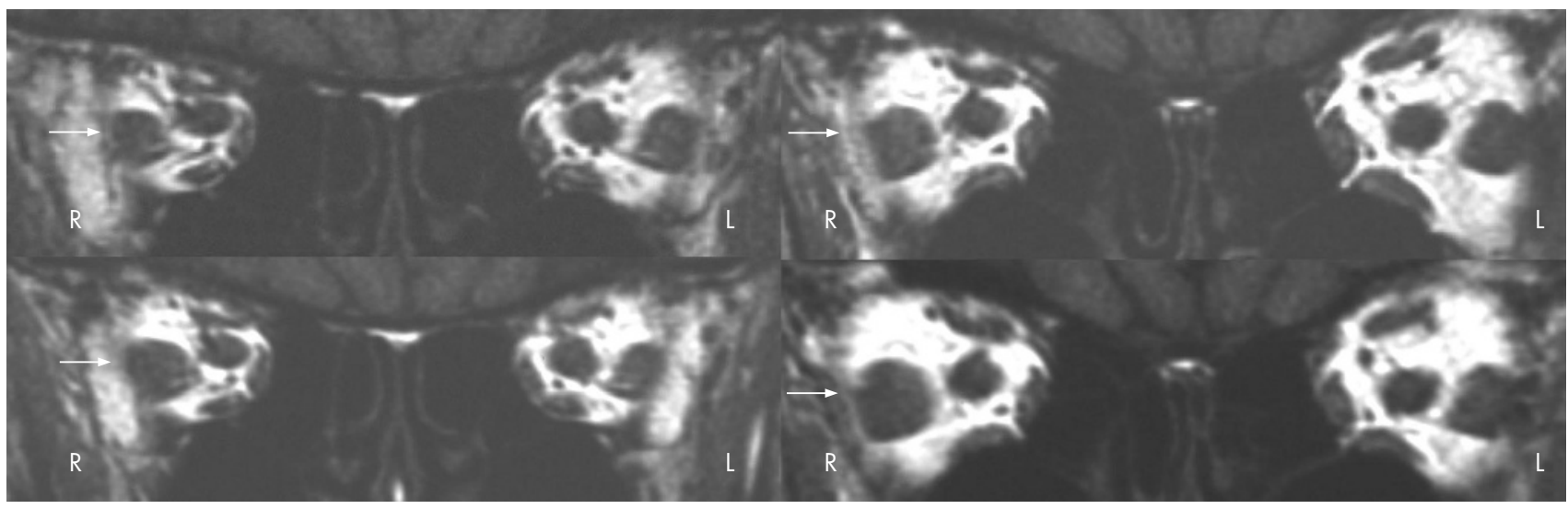

Figure 2 Magnetic resonance imaging T1-weighted coronal scans of the orbits showing images taken before injection (above), and images taken at 33 days after injection (below). The images on the left are at about $12 \mathrm{~mm}$ anterior to the orbital apex, and those on the right are at about $16 \mathrm{~mm}$ anterior to the orbital apex. The arrows indicate the right lateral rectus muscle. L, left; $R$, right.

Bupivacaine injected lateral rectus

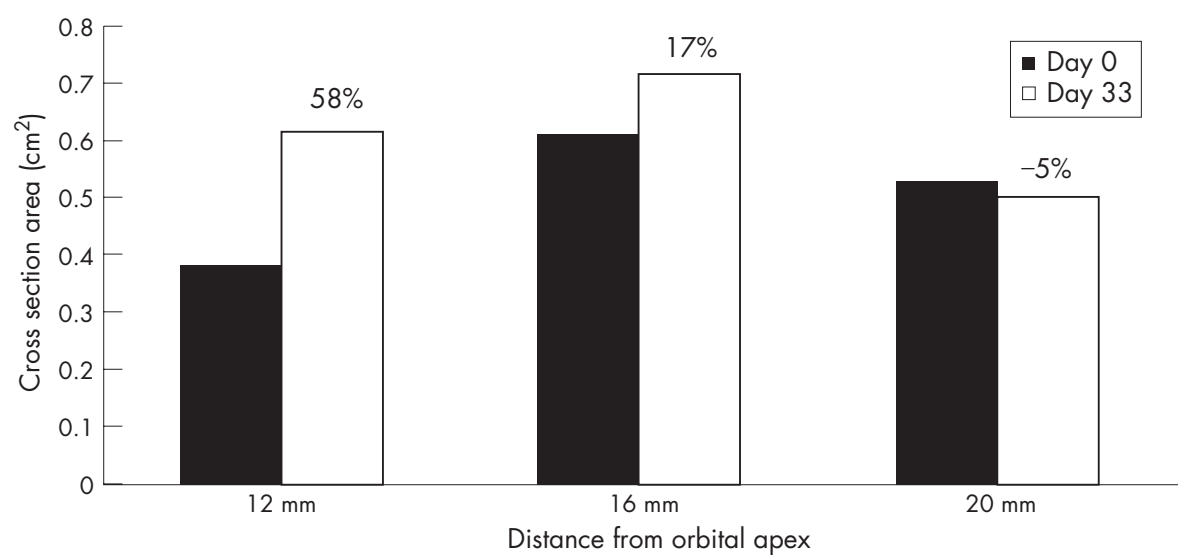

Figure 3 Right lateral rectus cross-sectional areas $\left(\mathrm{cm}^{2}\right)$ at 12,16 and $20 \mathrm{~mm}$ from the orbital apex, calculated using public domain ImageJ software. Pre-bupivacaine values are shown as solid bars; values at 33 days after injection are shown as open bars. The percentage change is indicated. scarring, the current putative causes for such strabismus, have not been documented by biopsy, nor found in animal injection studies. Furthermore, the modelling program-Orbit $1.8^{\mathrm{TM}}$ (Eidactics, San Francisco) indicates that muscle hypertrophy, not shortening or stiffening from scarring, can explain the overaction pattern characteristic of these cases. ${ }^{19}$ Hypertrophy also occurs after injection of denervated muscle in animals, auguring well for therapeutic trials in paretic strabismus. ${ }^{20}$ Accurate measurement of eye muscle sizes, forces and changes in alignment are under way in animals and humans in order to define the optimum volume of injection, drug dosage and location in the muscle for injection. It has not escaped our notice that extension of this approach to other muscles holds much promise.

\section{Authors' affiliations}

Alan B Scott, Danielle E Alexander, Joel M Miller, Smith-Kettlewell Eye Research Institute, San Francisco, California, USA

Funding: This work was supported by the Pacific Vision Foundation and by USPHS grants EY08313 and EY015314.

Correspondence to: A B Scott, Smith-Kettlewell Eye Research Institute, 2318 Fillmore Street, San Francisco, CA 94115, USA; abs@ski.org

Accepted 9 November 2006

Published Online First 29 November 2006

\section{REFERENCES}

1 Hall-Craggs EC. Early ultrastructural changes in skeletal muscle exposed to local anaesthetic bupivacaine (marcaine). Br J Exp Pathol 1980a;60:139-49.

2 Bradley WG. Muscle fiber splitting. In: Mauro A, eds. Muscle regeneration. New York: Raven Press, 1979:215-32.

3 Rosenblatt JD, Woods RI. Hypertrophy of rat extensor digitorum longus muscle injected with bupivacaine. A sequential histochemical, immunohistochemical, histological and morphometric study. J Anat 1992;181:11-27.

4 Plant DR, Beitzel F, Lynch GS. Length-tension relationships are altered in regenerating muscles of the rat after bupivacaine injection. J Appl Physiol 2005:98:1998-2003.

5 Park CM, Park SE, Oh SY. Acute effects of bupivacaine and ricin mAb35 on extraocular muscle in the rabbit. Curr Eye Res 2004;29:293-301.

6 Rainin EA, Carlson BM. Postoperative diplopia and ptosis. A clinical hypothesis based on the myotoxicity of local anesthetics. Arch Ophthalmol 1985; 103:1337-9.

7 Capo H, Guyton DL. Ipsilateral hypotropia after cataract surgery. Ophthalmology 1996;103:721-30.

8 Grimmett MR, Lambert SR. Superior rectus muscle overaction after cataract extraction. Am J Ophthalmol 1992;115:72-80.

9 Han SK, Kim JH, Hwang JM. Persistent diplopia after retrobulbar anesthesia. J Cataract Refract Surg 2004;30:1248-53.

10 Hamed LM, Mancuso A. Inferior rectus muscle contracture syndrome after retrobulbar anesthesia. Ophthalmol 1991;98:1506-12.

11 Rasband WS. ImageJ US. Bethesda, MD: National Institutes of Health, http:// rsb.info.nih.gov/ij/1997-2006.

12 Hall-Craggs EC. Survival of satellite cells following exposure to the local anesthetic bupivacaine (Marcaine). Cell Tissue Res 1980;209:131-5.

13 Grim M, Stingle J, Mrázková $O$. The impairment of muscle blood vessels after intramuscular injection of local anaesthetics. Histochem $J$ 1983;15:314-16.

14 Nonaka I, Takagi A, Ishiura S, et al. Pathophysiology of muscle fiber necrosis induced by bupivacaine hydrochloride (Marcaine). Acta Neuropathol (Berl) 1983;60:167-74. 
15 Komorowski TE, Shepard B Okland S, et al. An electron microscopic study of local anesthetic-induced skeletal muscle fiber degeneration and regeneration in the monkey. J Orthop Res 1990;8:495-503.

16 Antunes-Foschini RM, Ramalho FS, Ramalho LN, et al. Increased frequency of activated satellite cells in overacting inferior oblique muscles from humans. Invest Ophthalmol Vis Sci 2006;47:3360-5.

17 Christiansen SP, McLoon LK. The effect of resection on satellite cell activity in rabbit extraocular muscle. Invest Ophthalmol Vis Sci 2006;47:603-13.
18 Goldchmit M Scott AB. Avaliacao da motilidade extrinsca ocular de pacientes facectomizados sob anestesia retrobulbar. Arq Bras Offalmol 1994;57:114-16

19 Miller JM, Pavlovski DS, Shamaeva I. Orbit ${ }^{T M} 1.8$ gaze mechanics simulation. San Francisco: Eidactics, 1999.

20 Billington L, Carlson BM. The recovery of long-term denervated rat muscles after Marcaine treatment and grafting. J Neurol Sci 1996;144:147-55

\section{Clinical Evidence-Call for contributors}

Clinical Evidence is a regularly updated evidence-based journal available worldwide both as a paper version and on the internet. Clinical Evidence needs to recruit a number of new contributors. Contributors are healthcare professionals or epidemiologists with experience in evidence-based medicine and the ability to write in a concise and structured way.

Areas for which we are currently seeking contributors:

- Pregnancy and childbirth

- Endocrine disorders

- Palliative care

- Tropical diseases

We are also looking for contributors for existing topics. For full details on what these topics are please visit www.clinicalevidence.com/ceweb/contribute/index.jsp

However, we are always looking for others, so do not let this list discourage you.

Being a contributor involves:

- Selecting from a validated, screened search (performed by in-house Information Specialists) epidemiologically sound studies for inclusion.

- Documenting your decisions about which studies to include on an inclusion and exclusion form, which we keep on file.

- Writing the text to a highly structured template (about 1500-3000 words), using evidence from the final studies chosen, within 8-10 weeks of receiving the literature search.

- Working with Clinical Evidence editors to ensure that the final text meets epidemiological and style standards.

- Updating the text every 12 months using any new, sound evidence that becomes available. The Clinical Evidence in-house team will conduct the searches for contributors; your task is simply to filter out high quality studies and incorporate them in the existing text.

If you would like to become a contributor for Clinical Evidence or require more information about what this involves please send your contact details and a copy of your CV, clearly stating the clinical area you are interested in, to CECommissioning@bmigroup.com.

\section{Call for peer reviewers}

Clinical Evidence also needs to recruit a number of new peer reviewers specifically with an interest in the clinical areas stated above, and also others related to general practice. Peer reviewers are healthcare professionals or epidemiologists with experience in evidence-based medicine. As a peer reviewer you would be asked for your views on the clinical relevance, validity, and accessibility of specific topics within the journal, and their usefulness to the intended audience (international generalists and healthcare professionals, possibly with limited statistical knowledge). Topics are usually 1500-3000 words in length and we would ask you to review between 2-5 topics per year. The peer review process takes place throughout the year, and out turnaround time for each review is ideally 10-14 days.

If you are interested in becoming a peer reviewer for Clinical Evidence, please complete the peer review questionnaire at www.clinicalevidence.com/ceweb/contribute/peerreviewer.jsp 